\title{
Research on Strategies for Promoting Reform of English Translation Teaching in Colleges and Universities
}

\author{
Wei Zhao \\ School of Foreign Languages, Xi'an Shiyou University, Xi'an, 710065, China
}

Keywords: Colleges and universities; Translation teaching; Reform strategy

\begin{abstract}
Many problems to be improved exist in the efficient English translation teaching in China currently. College English teachers start to explore relevant reform strategies positively so as to improve the quality of classroom teaching and students' accomplishment of English translation and train more professional and high-quality talents for the society. The author analyzes and discusses the status and problems of English translation teaching in colleges and universities in detail and puts forward effective reform strategies in this paper.
\end{abstract}

\section{Introduction}

Enterprises have higher and higher requirements for professional talents with the constant development of society currently. Existing teaching patterns and methods can no longer adapt to development needs of students in English translation teaching in colleges and universities. To make students satisfy requirements of the society and enterprises better after graduation, English translation teachers and educational institutions start to explore effective reform strategies positively so as to produce more significant teaching achievements and improve students' English translation ability greatly.

\section{Status of English translation teaching in colleges and universities}

Since the reform and opening up, English has become the second language of Chinese gradually and played an increasingly important role in college education and teaching in China with the conduction of international cooperation and the strengthening of globalization tendency. However, the teaching quality is to be improved and some problems exist in teaching pattern and methods in view of English translation teaching in colleges and universities in China. It is imperative to promote the reform of English translation teaching in colleges and universities under such a situation.

\section{Weak teacher resources}

Foreign language is a special language. The learning process is often difficult for college students with the lack of foreign cultural literacy. There are high requirements for the expertise of relevant teachers in English translation teaching. Teacher resources are a vital part in factors influencing the teaching quality of foreign language. However, English teacher resources in Chinese colleges and universities are barely satisfactory in the current stage. The particularity of the subject and the quality of foreign language teachers to be improved result in the low quality of foreign language translation teaching in colleges and universities. Meanwhile, many English translation teachers have a low level of education. Among various subjects, English translation teaching has a strong comprehensiveness and requires relevant teachers to possess a high English and Chinese level and theoretical knowledge as well as abundant practical experience of translation. However, many English translation teachers cannot meet all conditions above due to various objective and subjective reasons, thus influencing the quality of English translation teaching in colleges and universities.

\section{Lack of rationality in curriculum setting}

Due to the particularity of English translation course, many colleges and universities offer it in the period from the first semester of sophomore year to junior year. Such arrangement lacks scientific rationality because the improvement of students' translation quality is closely related to English knowledge and meanwhile inseparable from Chinese foundation. However, some colleges and 
universities do not offer Chinese course in the freshman year, which is adverse to the improvement of students' Chinese quality and the accumulation of basic knowledge. Therefore, students often face various difficulties in the process of English translation. For example, though some students can understand the meaning of an English essay, they often fail to find the appropriate vocabulary or translate smoothly while translating it into Chinese, thus influencing the final translation quality and achievements.

\section{Irrational teaching objectives}

English translation teaching in colleges and universities mainly involve contents in two aspects: first, expand vocabularies, master grammatical knowledge and improve students' English foundation; second, improve students' abilities and skills in reading comprehension and English-Chinese translation. However, the main teaching objective of many English teachers is to improve students' passing rate in TEM4 and TEM6 and make students obtain the graduation certificate smoothly under the pressure of exam-oriented education. Thereby, English translation teachers are often committed to enriching students' problem-solving thought and improving students' abilities and skills in solving problems through exercise-stuffed teaching strategy, which imposing invisible pressure and heavy burden on students and meanwhile producing a low effect on the improvement of students' actual translation ability and quality and influencing the teaching quality and effect of English translation course seriously.

\section{Dull teaching contents and methods}

Teaching materials are very important in English translation teaching in colleges and universities and are an important basis of teaching. To train students' English translation ability better, college English translation teaching materials should integrate ideological level, practical utility and interestingness and have systematic planning for theoretical and basic knowledge for better study of students. However, teaching materials have dull contents in college English translation teaching currently. Teaching materials play a vital role in English translation class. Such teaching materials with dull contents are adverse to the study of students. The textbook-centered teaching pattern can hardly improve students' translation quality greatly and will even produce opposite effects because college students have a strong and active creative thinking; it is difficult to arouse their learning enthusiasm with dull English translation teaching contents and methods and they will even reject them.

\section{Reform strategies of college English translation teaching}

\section{Intensify teacher training}

Educational institutions are a base training and providing talents for the society. Relevant national sectors should be committed to improving the professional quality of teaching staff. Various maladies are exposed in college English translation teaching currently. Therefore, it is urgent to improve the professional quality of college English translation teachers. To improve students' English translation quality, colleges and universities should pay great attention to the introduction and training of high-quality English translation teachers.

Establish and improve talent introduction mechanism

To improve English translation teaching quality in colleges and universities, it is an effective means to establish and improve talent introduction mechanism and intensify teacher resources. Therefore, colleges and universities should introduce advanced educational talents positively with various methods and approaches. Due to multiple posts, English translation teachers in many colleges and universities cannot spend more time and energy on special researches on education and teaching, thus influencing the teaching quality. The establishment and improvement of talent introduction mechanism can alleviate this situation well. Meanwhile, to allow talents introduced to bring the initiative into full play, educational institutions should be committed to establishing the corresponding incentive mechanism and give rewards to teachers with significant teaching achievements and serious work so as to activate the initiative of teachers. 


\section{Intensify teacher training}

Some colleges and universities in China often pay little attention to teacher training. Therefore, it is very difficult to improve the professional quality of English translation teachers practically. Many institutions attach more importance to scientific research activities of teachers and put education and teaching in a secondary place. Even though some colleges and universities carry out the activity of teacher training, they put more emphasis on their mastery of relevant theoretical knowledge rather than practice. Moreover, the training of professional knowledge and moral accomplishment is lacking. Therefore, educational institutions must attach importance to the training of English translation teachers and make it an important item in the daily work. Meanwhile, it is necessary to innovate the traditional training mode, strengthen professional knowledge training and improve teachers' ability of combining theory and practice in the specific training process so as to greatly improve the classroom teaching quality of English translation subject and allow students to learn better.

\section{Improve curriculum setting}

Offer Chinese language and literature courses

Attention should be paid to scientificalness in the setting of translation course. Colleges and universities generally offer translation course in the sophomore year and mainly intensify students' basic English knowledge and train their abilities of listening, speaking, reading and writing in the freshmen year. Meanwhile, we should realize that abilities of listening, speaking, reading and writing alone cannot actually improve students' translation ability. Therefore, college English translation teachers should pay attention to improve students' connected use of English and Chinese. College Chinese, literature appreciation and writing courses can be offered in the freshmen year so that students can improve their Chinese accomplishment and study English translation subject better.

Arrange class period rationally

To actually improve students' ability of English translation, educational institutions should first arrange class period rationally and allocate time scientifically and rationally. Therefore, educational institutions and relevant education workers should innovate their concepts. In the current stage, many educational institutions pay more attention to the training of practical ability and do not advocate offering foreign language and literature courses. This concept is wrong in fact, which on the one hand influences the improvement of students' foreign cultural accomplishment, and on the other hand is adverse to the improvement of students' English translation ability. Therefore, educational institutions and relevant English teachers must pay attention to the rational arrangement of courses and attach importance to translation practice, theory and skill courses in practical teaching. Meanwhile, courses of the comparison between Chinese and foreign cultures and translation appreciation are essential. Educational institutions and English teachers should also make systematic arrangements on the class hour of courses above on this basis. First, translation practice courses can improve students' ability of connecting theory with practice and the class hour of such courses can account for $40 \%$ of total class hours. Second, class hours of translation theory and technology courses should account for $15 \%$. Other courses can be arranged according to the specific situation of students. Such scientific and rational course arrangement is conducive to strengthening the English foundation of students and improving their English translation ability gradually.

\section{Enrich teaching contents}

In English translation teaching in colleges and universities, many teachers do not pay attention to the improvement of teaching method and still use traditional teaching concepts and dull teaching contents, causing it difficult to improve students' English translation ability. To change this situation effectively, teachers must get rid of teaching program to a certain extent and teach pertinently based on the actual situation of students in the specific teaching process. Existing teaching program and materials of English translation course focus more on students' basic knowledge and have dull contents. Besides, examples in the teaching material lack the sense of times and vividness. To improve this situation effectively, college English translation teachers should be committed to enriching teaching contents, adding good translation appreciation in class and improving classroom interaction so as to attract students in teaching. Meanwhile, teachers can introduce foreign culture to students to arouse their interest. 


\section{Take modern teaching means}

In recent years, multimedia teaching has been widely applied in college education and teaching with the development of information technology. To allow students to learn and digest the knowledge learnt better, teachers can take multimedia teaching means to attract students through vivid pictures in English translation teaching. Besides, they can also play movies and online short plays to make students improve their English translation ability while watching movies. All this can allow students to understand the culture and custom of western countries and is conducive to improve their translation level.

\section{Pay attention to performance-type teaching}

Diversification has become a tendency and is manifested in many areas in the current society. More attention is paid to the diversification of methods and means in college education and teaching. English teachers should also take diversified teaching methods and use performance-type teaching mode in college English translation teaching. Performance-type teaching mode means that teachers guide students to set up relevant simulation scenes in class, put them in a specific background and ask them to present translation performance on this basis. This method can not only effectively train students’ English translation accomplishment, but also gradually improve their ability of handling affairs and practical ability. This teaching method is widely applied in foreign language teaching in western countries and has achieved good teaching effect in the current stage.

\section{Add classroom discussion}

Classroom teaching has vital practical significance in English translation teaching. It can arouse the initiative of students and allow them to participate in classroom teaching widely. One of the teaching objectives of English translation subject is to improve students' practical ability. By initiating discussions in English translation class, teachers can make the classroom atmosphere more active and allow students to express their opinions positively and actively, realize their own problems in English translation learning through the communication of different thoughts and values and learn other classmates' advantages and advanced thoughts positively. In this way, their ability of oral English expression can be greatly improved; meanwhile, their abilities of coping with emergencies, learning and communication are trained effectively. In short, classroom discussion is beneficial to the improvement of comprehensive accomplishment of college students.

\section{Conclusions}

In conclusion, many maladies exist in the current English translation teaching in Chinese colleges and universities, such as weak teacher resources, professional quality of many English translation teachers to be improved, dull teaching mode and contents and little attention paid to teacher training. To change this situation effectively, colleges and universities must be committed to introducing advanced educational talents, setting up the corresponding incentive mechanism and allowing teachers to glow in the teaching post. Meanwhile, educational institutions should also pay attention to teacher training so as to improve their theoretical knowledge, professional quality and professional ethics. In specific English translation teaching, teachers should positively innovate teaching pattern and pay attention to the effective use of multiple teaching methods so as to improve classroom teaching quality, improve students' English translation quality and turn them into professional talents required by social development needs in the new period.

\section{References}

[1] Zhang Qiongyao. Brief Analysis on Reform of Application Ability Training in College English Translation Teaching. Urban Tutor (First half of the month), 2014(5).

[2] Liu Zongyan. Superficial View on Reform of Application Ability Training in College English Translation Teaching. Success (Education Version), 2010(9). 
[3] Wang Xiaoji. Exploration on College MTI Teaching Reform - Take English Translation Teaching in Key Commerce and Science Colleges in Yangtze River Delta for Example. China Education Innovation Herald, 2014(2).

[4] Meng Jing. Discussion on Innovation of English Translation Teaching. Intelligence, 2014(15).

[5] Xie Xuelin. Intensify College English Translation Teaching and Promote College English Translation Reform - Take Jining Normal College for Example. English Square (Last ten-day period of the month), 2015(1). 